\title{
OUTCOME OF PRIMARY REPAIR IN TYPHOID ILEAL PERFORATION AT TERTIARY CARE HOSPITAL.
}

1. MBBS, MS, FRCS

Professor \& Dean Surgery

Allied PUMHSW Nawabshah

2. MBBS, MS

Associate Professor Surgical UnitPUMHSW Nawabshah.

3. MBBS, MS

Senior Registrar Surgical Unit-I PUMHSW Nawabshah.

4. MBBS, MS

Senior Registrar Surgical Unit-III PUMHSW Nawabshah

5. MBBS, FCPS

Associate Professor Surgical Unit-III PUMHSW Nawabshah.

6. MBBS, MS

Assistant Professor Surgical Unit-III PUMHSW Nawabshah.

Correspondence Address Dr. Abdul Hakeem Jamali Associate Professor Surgical Unit- I PUMHSW Nawabshah.

abdulhakeemjamali@gmail.com

Article received on:

03/05/2019

Accepted for publication:

$10 / 10 / 2019$
Gulshan Ali Memon', Abdul Hakeem Jamali², Sajjad Hussain Qureshi ${ }^{3}$ Altaf Hussain Ghumro4, Mashooq Ali Khowaja ${ }^{5}$, Inayat Ali Zardari ${ }^{6}$

ABSTRACT: Objectives: To detect the outcome of typhoid ileal perforation treated by primary repair at tertiary care hospital. Study Design: Cross sectional study. Setting: Surgical Department of PMC Hospital Nawabshah. Period: From August 2017 to December 2018. Material \& Methods: This study included total 70 patients. All patients were admitted from surgical OPD and emergency department of PMCH Nawabshah. Out of 70, $45(64.28 \%)$ were females and $25(35.71 \%)$ were male patients. Age ranged from 27 to 52 and 24 to 47 in females and males respectively. The common presentation was pain in whole abdomen along with distention and fever, vomiting. Plain X ray chest/ Abdomen and ultra sonography showed gas under diaphragm. Primary repair was done and also other surgical options but our study included only the postoperative outcomes of primary repair of typhoid ileal perforation. A few complications were detected after primary repair of the gut perforation. Results: Total 70 patients were included in this study. $45(64.28 \%)$ were females and $25(35.71 \%)$ were male patients. In females, $25(55 \%)$ were found single perforations of less than $1 \mathrm{~cm}$ whereas $7(15.5 \%)$ had size of perforation less than $1.5 \mathrm{~cm}$. In 25 males, $11(44 \%)$ had single perforations of less than $1 \mathrm{~cm}$ in size. $2(8 \%)$ had $<1.5 \mathrm{~cm}$ size perforations and $12(48 \%)$. Over all complication rate in this study was $26 \%$. Conclusion: Primary repair is the best surgical option to treat typhoid ileal perforation in selected patients with least postoperative complications.

Key words: Ileostomy, Morbidity and Mortality, Primary Repair, Typhoid Ileal Perforation.

Article Citation: Memon GA, Jamali AH, Qureshi SH, Ghumro AH, Khowaja MA, Zardari IA. Outcome of primary repair in typhoid ileal perforation at Tertiary Care Hospital. Professional Med J 2020; 27(6):1128-1132.

DOI: 10.29309/TPMJ/2020.27.06.3671

\section{INTRODUCTION}

Humans can survive only 3 minutes without air and 3 days without water. Human body works like a machine and it is necessary to accomplish its needs for its maintenance. Water is essential element to life. Human body is composed of $70 \%$ water so it is imperative for it to be hydrated. Fresh, clean, and alkaline water is to be used in order to hydrate body and maintain $\mathrm{pH}$ level to keep body healthy. If contaminated/infected water is used, many diseases erupt and the most common and fatal of all is typhoid fever. ${ }^{1}$

Typhoid fever has widely remained problematic for humanity throughout the world particularly for third world countries including Pakistan. It is caused by an organism named Salmonella Typhi that is, though, least likely affecting people of developed countries but is continuously enhancing the health issues for tropical countries. ${ }^{2}$ Seldom does salmonella paratyphi cause typhoid disease. Human is the sole reservoir of salmonella Typhi. Transmission is through fecooral route. This disease occurs in phases with its complications as it progresses. ${ }^{3}$ First week is the bacteremic phase causing fever and chills. The disease progresses to reticuloendothelial involvement with rash, abdominal pain and prostration in $2^{\text {nd }}$ week. Third week witnesses the ulceration in Payer's patches with intestinal bleeding and perforation. ${ }^{4}$ The incidence of perforation ranges between $0.8 \%$ to $18 \%$. Though intestinal bleeding is the common complication, enteric perforation is the common cause of high morbidity and mortality that ranges between $5 \%$ and $62 \%$. Ulcers are usually longitudinal located within $45 \mathrm{cms}$ of ileocaecal junction. ${ }^{5}$ 
Its incidence varies in different regions of the globe. South America, Eastern European countries, Middle East, and all African countries are endemic regions for typhoid fever. It is commonly detected in Turkey as nearly more than 10000 patients are contacting typhoid fever every year. ${ }^{6}$

The Surgical common complications of typhoid fever are intestinal perforation, bleeding, cholecystitis, osteomyelitis, and abscess. The rare complications included are pancreatitis, hepatic and splenic abscesses, pleural effusion and orchitis. Among all, intestinal perforation is the common and fatal to human being if not treated early. It is serious surgical complication in developing countries. The incidence of IP ranges from $0.6 \%$ to $4.9 \%$. In endemic regions it varies from $4.5 \%$ and 75 percent. $^{7}$

Intestinal perforation is the fatal complication of enteric fever and commonly present with abdominal pain, distention of abdomen, high grade fever, vomiting, lethargy, tenderness of abdomen on examination. Patients are usually dehydrated, pale and toxic in look. Tachycardia and tachypnea are mostly found in these patients. ${ }^{8}$

Post-operative mortality increases to $80 \%$ in patients with delayed presentation. Blood culture is the most important diagnostic method. Faeces may also contain organisms, which can be cultured. A serological test, Widal reaction detects antibodies formed against bacteria. There is free gas under diaphragm on plain $X$ ray abdomen. Widal-Grube agglutination test is positive at 1:600 dilation, and per operative findings are also matched with pre-operative diagnostic investigations. ${ }^{9}$

The surgical options are decided on multiple factors like size, site and number of perforation, time of presentation, degree of contamination of abdominal cavity, condition of intestine and general condition of the patient either septic or non-septic. If the size of perforation is less than 1.5 to $2 \mathrm{~cm}$, primary closure is done otherwise other options like resection anastomosis and covering ileostomy are made after the repair of primary perforations. ${ }^{10}$

The rationale of our study is to assess the outcome of primary repair of typhoid perforation aimed at preventing the patient from psychological trauma and economic burden of stoma formation.

\section{MATERIAL \& METHODS}

This is a cross sectional study of 70 patients admitted through Emergency/ Surgical Outpatient department (SOPD) in surgical Department of Peoples University of Medical and Health Sciences for Women (PUMHSW) Nawabshah. This study was conducted from August 2017 to December 2018. This is tertiary care hospital receiving and treating the patients of not only Sindh but also other provinces of Pakistan.

All the patients were suffering from abdominal pain, distention and fever, vomiting and tenderness of abdomen. Local examination of abdomen was done to diagnoses the disease and the systemic examination was to assess the general condition of the patient. X-Ray chest/ abdomen along with Ultrasound of Abdomen was done to help confirm the diagnosis of the disease. $X$ rays showed gas under right dome of diaphragm.

\section{Inclusion Criteria}

For primary repair were early presentation within 24 hours, good general health status of patient and on the laparotomy primary repair was opted when there was single small perforation quite away from ileocecal junction with minimum degree of peritoneal soiling and healthy intestinal wall surrounding perforation.

\section{Exclusion Criteria}

For primary repair of typhoid ileal perforation were delayed presentation with septicemic shock and multi organ failure, multiple perorations, large size perforations and perforation very near to ileocecal junction, moderate to massive peritoneal soiling unhealthy bowel wall surrounding perforation and moribund patients.

\section{RESULTS}

In this study, total 70 patients were included from all surgical wards of $\mathrm{PMCH}$ Nawabshah. Out of 
70,45 (64.28\%) were females and 25 (35.71\%) were male patients.

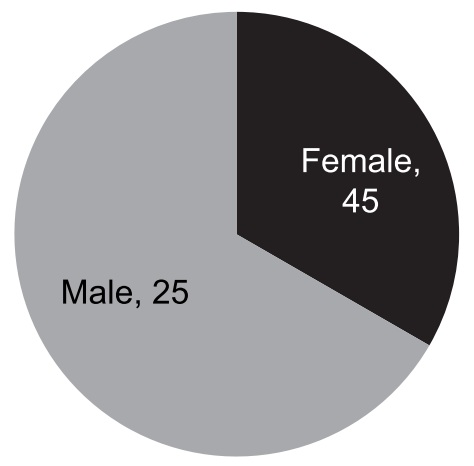

Female 45 (64.28\%)

Male $25(35.72 \%)$

Pie Chart.

Out of 45 females, 25 (55\%) were found single perforations of less than $1 \mathrm{~cm}$ and 2 feet away from ileocaecal junction whereas 7 (15.5\%) patients had size of perforation less than $1.5 \mathrm{~cm}$. $13(28.88 \%)$ patients had single/ two perforations of not more than 2 to $2.5 \mathrm{~cm}$ size as is shown in Table-l below. The age range of females affected was between 27 to 52 years.

Out of 25 male patients, 11 (44\%) patients single perforations of less than $1 \mathrm{~cm}$ in size. $2(8 \%)$ patients had $<1.5 \mathrm{~cm}$ size perforations and 12 $(48 \%)$ had not more than $2.5 \mathrm{~cm}$ size perforations as is shown in Table-ll below. These patients had not contaminated abdominal cavity. The condition of the ileum was good. The age of males affected ranged between 24 to 47 years.

The procedure of primary repair had multiple complications. These were fistula formation, infected wound, and paralytic ileus. Only 2 $(2.8 \%)$ patients presented with fecal fistula and only $5(7.14 \%)$ developed postoperative wound infection. $10(14.2 \%)$ patients developed prolonged paralytic ileus that was relieved by treatment later on conservatively. None of the patient presented with burst abdomen. Table-III

\begin{tabular}{|l|c|c|c|c|}
\hline \multicolumn{1}{|c|}{ Sr. No. } & No of Patients & Percentage & Size of Perforation & Surgical Option Done \\
\hline 1 & 25 & $55.5 \%$ & $<1 \mathrm{~cm}$ & Primary Repair \\
\hline 2 & 7 & $15.5 \%$ & $<1.5 \mathrm{~cm}$ & Primary repair \\
\hline 3 & 13 & $28.88 \%$ & $<2$ to $2.5 \mathrm{~cm}$ & Primary repair \\
\hline Total & 45 & $100 \%$ & \\
\hline \multicolumn{2}{|r|}{ Table-l. } \\
\hline
\end{tabular}

\begin{tabular}{|l|c|c|c|c|}
\hline \multicolumn{1}{|c|}{ Sr. No. } & No of Patients & Percentage & Size of Perforation & Surgical Option Done \\
\hline 1 & 11 & $44 \%$ & $<1 \mathrm{~cm}$ & Primary Repair \\
\hline 2 & 2 & $8 \%$ & $<1.5 \mathrm{~cm}$ & Primary repair \\
\hline 3 & 12 & $48 \%$ & $>2$ to $2.5 \mathrm{~cm}$ & Primary repair \\
\hline Total & 25 & $100 \%$ & \\
\hline \multicolumn{2}{|c|}{ Table-II. } \\
\hline
\end{tabular}

\begin{tabular}{|l|c|c|c|}
\hline \multicolumn{1}{|c|}{ Sr. No. } & Complication & No of Patients & Percentage \\
\hline 1 & Fecal fistula & 2 & $2.8 \%$ \\
\hline 2 & Wound infection & 5 & $7.14 \%$ \\
\hline 3 & Paralytic ileus & 10 & $14.2 \%$ \\
\hline 4 & Wound dehiscence & 0 & 0 \\
\hline 5 & Intra-abdominal abscess & 2 & $2.8 \%$ \\
\hline Total & & 17 & $26.22 \%$ \\
\hline & & Table-III. & \\
\hline
\end{tabular}




\section{DISCUSSION}

Typhoid ileal perforation is the common surgical emergency presented as acute abdomen throughout the globe particularly in the developing counties. Its prognosis solely relies on the clinical features and the time of presentation apart from per operative findings of the disease. Early presentation has good prognosis with primary repair of the ileal perforation. But it is matter of fact that patients in our set up come too late even in state of septicemia and multi organ dysfunction. They have bad prognosis. Recent advances have proved that surgical treatment is the best option to treat the complicated typhoid disease. ${ }^{11}$

In one study, two surgical options were observed and male incidence was found to be increased but in our study only one surgical option is applied and female's ratio was seemed to be affected more by enteric fever as compared to male. A study showed the age ratio of patients suffering from ileal perforation was from 26-31 years. In another study conducted in Pakistan, the age ranged from 30-31 years but in our study the female age ranged from 27 to 52 years whereas in males it was from 24-47 years with average age of 40 years. Middle aged male and female patients suffered from this disease in our study. ${ }^{12}$

Regarding the postoperative complications, one study showed higher rates of complications when compared with ileostomy but in our study, the complications rate was low. A study conducted in Pakistan showed better prognosis in primary repair as compared to ileostomy regarding the mortality of the patients. The same is found in our study as none of patient died after primary repair. $^{12}$

With regard the duration of hospital stay, a study showed the decrease in duration of hospital stay in case of loop ileostomy whereas the patients of primary repair stayed more days who underwent in paralytic illeus. Same was also seen in another international study. The hospital stay of our patients was from 3 to 10 days but it was same as is in other studies. ${ }^{13}$

\section{CONCLUSION}

Typhoid ileal perforation is still lethal condition and always needs surgical treatment. There are numerous operative procedures to treat typhoid ileal perforation but without universal consensus. In our study patients who presented within 24 hours, having good general health status without septicemia and multiorgan failure and on the laparotomy when single smaller perforation quite away from ileocecal junction with minimum degree of peritoneal soiling and healthy intestinal wall surrounding perforation Primary repair seems to be best surgical option with least postoperative complications.

Copyright $\odot 10$ Oct, 2019.

\section{REFERENCES}

1. Saxe JM, Cropsey R. Is operative management effective in treatment of perforated typhoid? The American journal of surgery. 2005 Mar 1; 189(3):342-4.

2. Adesunkanmi AR, Badmus TA, Ogundoyin $\mathrm{O}$. Causes and determinants of outcome of intestinal perforations in a semiurban African community. Annals of the College of Surgeons of Hong Kong. 2003 Nov; 7(4):116-23.

3. Ahmad T, Khan MI, Hussain N, Siddiqui E, Islam ZU. Perforation operation interval as a prognostic factor in typhoid ileal perforation. J Surg Pakistan (International). 2009 Jan; 14:11-4.

4. Sarsu SB, Karapur A. lleal perforation caused by typhoid fever. Ulutas Med J. 2015; 1:86-9.

5. Shrivastava D, Jain AK, Gharde P, Sharma DB, Verma RS. Typhoid intestinal perforation in Central India-a surgical experience of 155 cases in resource limited setting. IJBAR. 2014; 5(12):600-4.

6. Agu K, Nzegwu M, Obi E. Prevalence, morbidity, and mortality patterns of typhoid ileal perforation as seen at the University of Nigeria Teaching Hospital Enugu Nigeria: An 8-year review. World Journal of Surgery. 2014 Oct 1; 38(10):2514-8.

7. Malik AK, Nomani AZ, Qureshi AU, Gondal KM. Factors associated with survival in patients of enteric perforations; A retrospective analysis of 73 patients. Annals of King Edward Medical University. 2010; 16(4):233. 
8. Mishra M, Singh P, Tripathi A. Typhoid ileal perforation: Comparative study of ileostomy versus primary ileal repair and associated morbidity and mortality. International Surgery Journal. 2018 Aug 25; 5(9):312933.

9. Wani MD, Mir SA, Bhat JA, Gul S, Maqbool U, Moheen HA. Hyperbilirubinemia, C-reactive protein and ultrasonography as predictors of appendiceal perforation: A prospective study. Saudi Surgical Journal. 2014 Jan 1; 2(1):1.

10. Munghate A, Kumar A, Mittal S, Singh H, Sharma J, Yadav M. Acute physiological and chronic health evaluation ii score and its correlation with three surgical strategies for management of ileal perforations. Journal of surgical technique and case report. 2015; $7(2): 32-6$.
11. Siddiqui FG, Shaikh JM, Soomro AG, Bux K, Memon AS, Ali SA. Outcome of ileostomy in the management of ileal perforation. JLUMHS. 2008 Sep 1; 7:168-72.

12. Obaro SK, Hassan-Hanga F, Olateju EK, Umoru D, Lawson L, Olanipekun G, Ibrahim S, Munir H, Ihesiolor G, Maduekwe A, Ohiaeri C. Salmonella bacteremia among children in central and northwest Nigeria, 2008-2015. Clinical Infectious Diseases. 2015 Oct 7; 61(suppl_4):S325-31.

13. Mogasale V, Desai SN, Mogasale VV, Park JK, Ochiai RL, Wierzba TF. Case fatality rate and length of hospital stay among patients with typhoid intestinal perforation in developing countries: A systematic literature review. PLoS One. 2014 Apr 17; 9(4):e93784.

\begin{tabular}{|c|c|c|c|}
\hline \multicolumn{4}{|c|}{ AUTHORSHIP AND CONTRIBUTION DECLARATION } \\
\hline Sr. \# & Author(s) Full Name & Contribution to the paper & Author(s) Signature \\
\hline 1 & Gulshan Ali Memon & Conception and design. & \\
\hline 2 & Abdul Hakeem Jamali & $\begin{array}{l}\text { Critical revision of the article for } \\
\text { impiortant intellectual content. }\end{array}$ & \\
\hline 3 & Sajjad Hussain Qureshi & Data collection & \\
\hline 4 & Altaf Hussain Ghumro & Drafting of the article & 侪- \\
\hline 5 & Mashooq Ali Khowaja & Statistical experties & \\
\hline 6 & Inayat Ali Zardari & Performa filling. & Baxary \\
\hline
\end{tabular}

